\title{
Safety planning-type interventions for suicide prevention: meta-analysis
}

Chani Nuij, Wouter van Ballegooijen, Derek de Beurs, Dilfa Juniar, Annette Erlangsen, Gwendolyn Portzky, Rory C. O'Connor, Johannes H. Smit, Ad Kerkhof and Heleen Riper

\section{Background}

Safety planning-type interventions (SPTIS) for patients at risk of suicide are often used in clinical practice, but it is unclear whether these interventions are effective.

\section{Aims}

This article reports on a meta-analysis of studies that have evaluated the effectiveness of SPTIs in reducing suicidal behaviour and ideation.

\section{Method}

We searched Medline, EMBASE, PsycINFO, Web of Science and Scopus from their inception to 9 December 2019, for studies that compared an SPTI with a control condition and had suicidal behaviour or ideation as outcomes. Two researchers independently extracted the data. To assess suicidal behaviour, we used a random-effects model of relative risk based on a pooled measure of suicidal behaviour. For suicidal ideation, we calculated effect sizes with Hedges' $g$. The study was registered at PROSPERO (registration number CRD42020129185).

\section{Results}

Of 1816 unique abstracts screened, 6 studies with 3536 participants were eligible for analysis. The relative risk of suicidal behaviour among patients who received an SPTI compared with control was 0.570 ( $95 \% \mathrm{Cl} 0.408-0.795, P=0.001$; number needed to treat, 16). No significant effect was found for suicidal ideation.

\section{Conclusions}

To our knowledge, this is the first study to report a meta-analysis on SPTIS for suicide prevention. Results support the use of SPTIS to help preventing suicidal behaviour and the inclusion of SPTIS in clinical guidelines for suicide prevention. We found no evidence for an effect of SPTIs on suicidal ideation, and other interventions may be needed for this purpose.

\section{Keywords}

Suicide; suicide prevention; safety planning; meta-analysis.

\section{Copyright and usage}

(c) The Author(s), 2021. Published by Cambridge University Press on behalf of the Royal College of Psychiatrists. This is an Open Access article, distributed under the terms of the creative Commons Attribution licence (http://creativecommons.org/ licenses/by/4.0/), which permits unrestricted re-use, distribution, and reproduction in any medium, provided the original work is properly cited.

\section{Background}

Suicidal behaviour is a significant public health issue worldwide, resulting in an estimated 16 million suicide attempts and 800000 suicides per year. ${ }^{1}$ For every person who dies by suicide, more than 20 others make a non-fatal attempt, ${ }^{2}$ and many more have serious thoughts about ending their life. ${ }^{3}$ Suicidal ideation and suicidal behaviour (including both fatal and non-fatal suicide attempts) thus constitute a substantial disease burden. This underlines the importance of suicide prevention. ${ }^{4}$

There is an increasing body of evidence in support of several psychological treatments for suicide prevention, including cognitive-behavioural therapy and dialectical behaviour therapy. ${ }^{5,6}$ In recent years, brief interventions, defined as up to three encounters between a patient and (para-)professional, have also been linked to reduced risks of suicidal behaviour. ${ }^{7,8}$

\section{Safety planning-type interventions}

One group of brief interventions consists of safety planning-type interventions (SPTIs). The technique in SPTIs is called safety planning, and is derived from cognitive therapy and cognitive-behavioural therapy for suicide prevention. ${ }^{9,10}$ The goal of safety planning is to reduce the imminent risk of suicidal behaviour by constructing a predetermined set of coping strategies and sources of support in a plan. ${ }^{10,11}$ During a crisis, an individual may use these strategies to avert their thoughts about suicide and manage their suicidal urges. ${ }^{11}$ Since its introduction, safety planning has become an integral part of standard clinical care for people at risk of suicide, and it is being used as a brief standalone intervention. ${ }^{11}$

The plan that is constructed in safety planning has been referred to in a number of ways, including 'safety plan', 11 'crisis response plan'12 and 'coping card', ${ }^{13}$ but in essence they all cover the same psychological technique. The current review uses the term SPTIs to summarise the entire range of brief interventions in which safety planning is applied. The strategies and sources of support are embedded in what we will call a safety plan.

Interventions of the safety planning type are recommended as best practice by the National Institute for Health and Care Excellence (https://www.nice.org.uk/guidance/cg133) in the UK, and the Suicide Prevention Resource Center (www.sprc.org) in the USA. Historically, the use of safety plans in clinical practice seems to be based on clinicians' beliefs about their effectiveness, ${ }^{14,15}$ rather than on empirical evidence. ${ }^{16}$ Individual trials on the effectiveness of SPTIs have yielded conflicting results, ${ }^{17,18}$ whereas meta-analyses of studies that included SPTIs have focused on brief interventions more broadly. ${ }^{7,8}$ Although the latter have made an important contribution to the literature, they did not include all published trials on SPTIs, and did not report on the effectiveness of SPTIs specifically. ${ }^{7,8}$

\section{Aims}

The purpose of this study was to conduct a meta-analysis to assess whether SPTIs for suicide prevention are linked to reductions in first, suicidal behaviour (fatal and non-fatal suicide attempts), and second, suicidal ideation.

\section{Method}

Before study commencement, the study protocol was registered in the international Prospective Register of Systematic Reviews at the University of York (PROSPERO; registration number 
CRD42020129185). We modified the protocol in two respects. First, to more accurately reflect the focus of the study, we chose to use the term 'safety planning-type' instead of 'crisis management'. Safety planning-type is a better description of a personalised plan. Second, to facilitate interpretation, we calculated relative risks instead of odds ratios. As the underpinning calculation is similar to that for an odds ratio, the use of relative risks should not alter the findings. The Preferred Reporting Items for Systematic Reviews and Meta-Analysis (PRISMA) guidelines were followed for reporting the meta-analysis; ${ }^{19}$ the PRISMA checklist is reproduced in Supplementary Appendix 1 available at https://doi.org/ 10.1192/bjp.2021.50.

\section{Search strategy}

A systematic literature search was developed and performed in collaboration with a librarian. We searched the following databases from their inception to 9 December 2019: Medline (PubMed. com), EMBASE (embase.com), PsycINFO (EBSCO), Web of Science (Clarivate) and Scopus (Elsevier). The search strategy included $\mathrm{MeSH}$ terms and free-text terms relating to suicide, safety management, crisis intervention and prevention. The actual terms used in the search strategy for PubMed are listed in Supplementary Appendix 2; these were subsequently adapted for other databases. We additionally conducted hand searches of reference lists in identified publications and consulted experts in the field to identify additional publications (C.N.).

\section{Selection of studies}

The following inclusion criteria were applied: (a) a brief standalone intervention based on safety planning for suicide prevention was delivered; (b) the safety plan contained, as a minimum, personalised coping strategies and sources of support; (c) the safety plan was the primary element of the intervention; (d) a control condition was applied (including treatment as usual (TAU) or another treatment) and (e) the study reported on at least one of the outcomes of suicidal behaviour, suicide attempts, suicides or suicidal ideation. The outcome 'suicidal behaviour' (suicide attempts, fatal suicides or both combined) was defined as the number of participants who engaged in suicidal behaviour as defined by the original authors of the included studies. As a result, suicide attempts were either identified from medical records, identified from clinical notes (recorded by a clinician or gatekeeper) or reported by patients (via questionnaires or during interviews). Suicidal ideation was reported by patients and assessed on the basis of questionnaires or clinical interviews. There were no restrictions on study participants in terms of age or disorder, as long as they were at risk of suicide (on the basis of current suicidal ideation or a recent suicide attempt). Studies were excluded if they were not written in English or not peer-reviewed.

All identified studies were exported to EndNote X9 for Windows (Clarivate, Boston, USA; see https://endnote.com/), where duplicates were removed. The studies were subsequently imported into Covidence software for Windows (covidence, Melbourne, Australia; see https://www.covidence.org/) for managing the meta-analysis. To determine study eligibility, all titles and abstracts were screened independently by two researchers (C.N. and W.v.B.), who also conducted the second full-text screening independently. Disagreements or uncertainties were discussed with the senior researcher supervising the project (H.R.).

\section{Data extraction}

We started data extraction on 4 February 2020. A data extraction sheet was used to collect information regarding setting, participants, design, intervention and control group. Intention-to-treat data were extracted when possible. The data were extracted independently by two authors (C.N. and D.J.). In the event of disagreement, a third author was consulted (W.v.B.). The corresponding authors were contacted if studies did not list the necessary data to conduct the quantitative analyses. If no additional data were available, the study was omitted from further analyses.

\section{Statistical analysis}

For our primary outcome of suicidal behaviour measured as the combined rate of suicide attempts and suicide deaths, effect sizes were calculated based on the number of participants in the intervention and control condition who had engaged in suicidal behaviour during the follow-up period. Effects were based on relative risk and its $95 \%$ confidence interval, calculated as the ratio of the probability of suicidal behaviour in the intervention condition to its probability in the control condition. A relative risk lower than 1 would indicate that persons receiving an SPTI had lower risks of suicidal behaviour than controls, whereas a relative risk higher than 1 would indicate a higher risk and a relative risk of 1 would indicate a similar risk for the two groups.

For the secondary outcome of suicidal ideation, we extracted mean (s.d.) scores and presented them as standardised effect sizes, using Hedges' $g$. Hedges' $g$ was calculated by subtracting the average score at follow-up for suicidal ideation by persons receiving the intervention from the average score of those in the control condition, and dividing the result by the pooled standard deviation. An effect size of 0.8 was considered a large effect, 0.5 was considered moderate and 0.2 was considered small. ${ }^{20}$

To further quantify effects, the number needed to treat (NNT), which summarises the number of patients who would need to be treated in order for one additional patient not to engage in suicidal behaviour, was calculated if a significant outcome effect supported this. ${ }^{21}$

To account for differences between study populations, interventions and control conditions, we performed a random-effects metaanalysis. In studies where multiple intervention conditions were investigated, the control condition was split into two or more subgroups, dividing the number of control participants by the number of intervention conditions.

Outliers were evaluated by examining whether the $95 \%$ confidence intervals of individual studies overlapped with the $95 \%$ confidence interval of the pooled effect size. In the absence of an overlap, the study would be identified as an outlier. Publication bias was assessed by visually examining the funnel plots of the outcome measures. ${ }^{22}$ We used Egger's linear regression test of the intercept to examine whether bias captured by the funnel plot was significant, and performed Duval and Tweedie's trim-and-fill procedure to assess for potential publication bias. ${ }^{23,24}$

As a test of homogeneity of effect sizes, we calculated the $I^{2}$ statistic, an indicator of variation between studies. No observed heterogeneity is shown as $0 \%$, and larger values suggest an increasing level of heterogeneity, with $25 \%$ as low, $50 \%$ as moderate and $75 \%$ as high. ${ }^{25}$ We further estimated the $95 \%$ confidence interval around $I^{2}$, using the non-central $\chi^{2}$-based approach within the heterogi module in Stata for Windows version 16.0. ${ }^{26,27}$ Factors that may have introduced heterogeneity in individual studies were investigated with subgroup analyses. Based on study characteristics of the included studies, subgroup analyses were performed with the following potential moderators: methodological quality, setting and population.

Statistical significance was set at $P<0.05$. All of these analyses were conducted with the software Comprehensive MetaAnalysis for Windows version 3.3.070 (Comprehensive MetaAnalysis, Englewood, USA; see https://www.meta-analysis.com/), except for the heterogeneity $\left(I^{2}\right)$ and its confidence interval, for which we used Stata. ${ }^{26,27}$ 


\section{Quality assessment}

The methodological quality was determined with the Cochrane Collaboration's Risk-of-Bias Tool $2,{ }^{28}$ which considers risk of bias across five domains: the randomisation process, deviations from the intended interventions, missing outcome data, measurement of outcome and selection of the reported results. The risk of bias for each domain was scored as low, moderate or high. The overall bias was considered high when one of the domains was scored as high. The risk of bias assessment was performed independently by two authors (C.N. and D.J.), with a third author (W.v.B.) consulted in case of disagreement.

\section{Results}

\section{Study selection}

The systematic search identified 3463 studies, and one additional study was added after the hand-searching of relevant journals. After removal of duplicates, 1816 studies remained. After evaluation of titles and abstracts against the inclusion criteria, 1782 studies were deemed not eligible. We retrieved 34 full-text articles for further review, from which 6 studies were ultimately included in the meta-analysis (see PRISMA flow chart in Fig. 1). Corresponding authors of four studies were contacted to retrieve additional information necessary for our meta-analysis, of which two authors replied.

\section{Study characteristics}

The six studies were conducted in three different countries (USA, $n=3$; Taiwan, $n=2$; Switzerland, $n=1$ ) and published between 2013 and 2018 (Table 1). ${ }^{12,13,17,18,29,30}$ All studies reported rates for suicide attempts and suicides. Three studies additionally reported on suicidal ideation. ${ }^{12,13,30}$ Intention-to-treat data could be extracted from five studies, ${ }^{12,13,17,18,30}$ and one study had only study completers' data available. ${ }^{29}$

The meta-analysis included four randomised controlled trials, ${ }^{12,13,29,30}$ a non-randomised controlled trial ${ }^{18}$ and one study with an interrupted time-series design. ${ }^{17}$ In four studies, safety planning was assessed as an add-on to TAU. ${ }^{13,18,29,30}$ Two studies compared a safety plan as a standalone intervention to TAU and included two intervention arms. ${ }^{12,17}$ One of those studies used a safety plan in both conditions, ${ }^{12}$ and the other in only one condition. ${ }^{17}$ Here, the intervention condition without the safety plan was omitted from the meta-analysis. This yielded a total of seven comparisons in the current meta-analysis.

In all, 3536 participants $(n=2096$ in intervention conditions; $n=1440$ in control conditions) aged $\geq 18$ years (average age range of $26-48$ years) were enrolled in the studies. More male (63.2\%) than female participants were included, and half of the participants
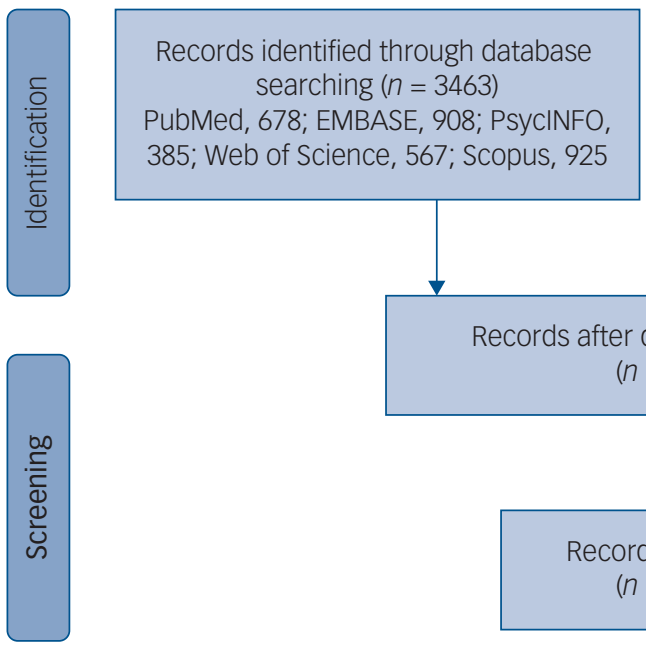

Records after duplicates removed $(n=1816)$
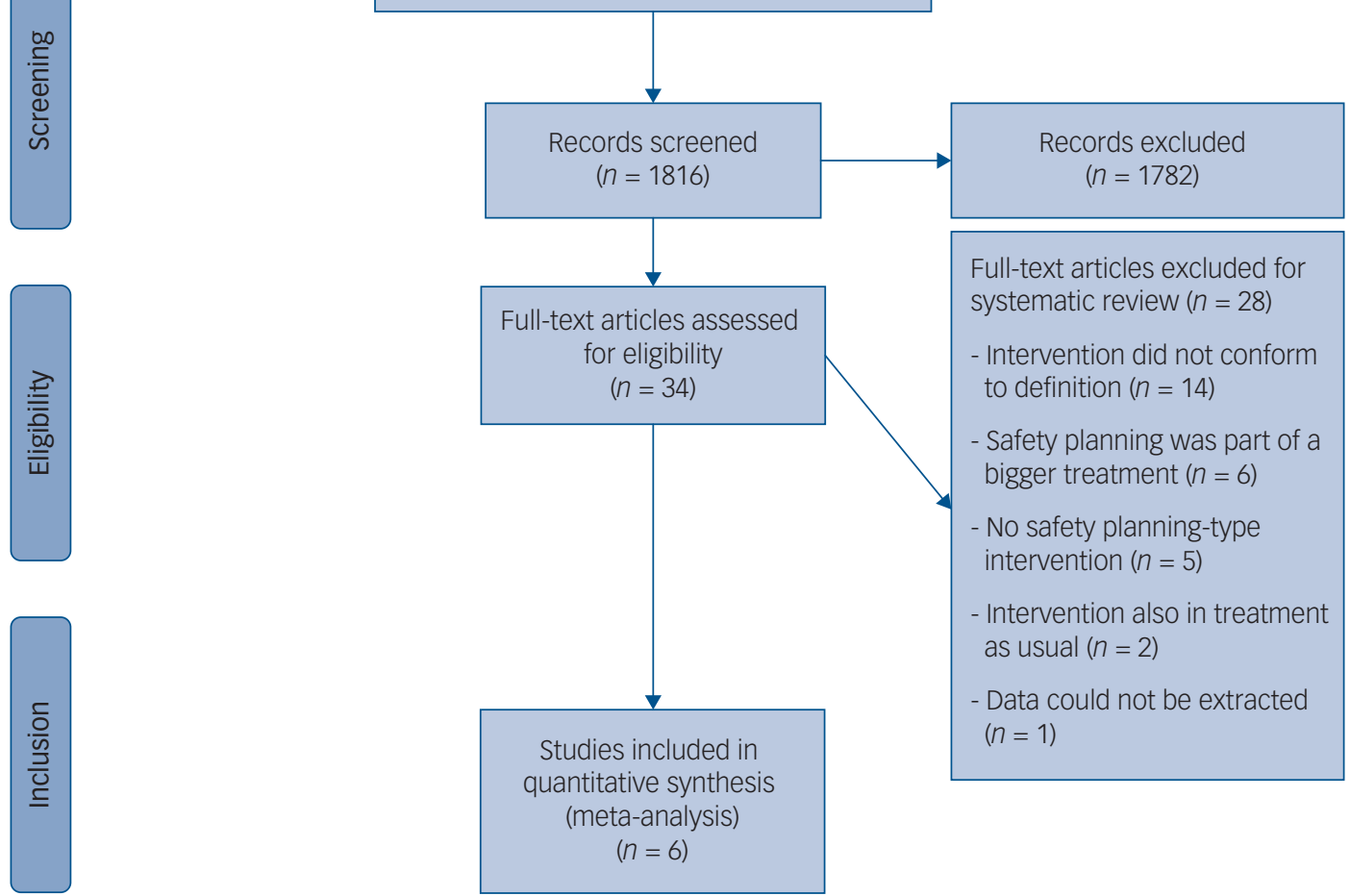

(meta-analysis)

$$
(n=6)
$$

Additional records identified through other sources $(n=1)$ 


\begin{tabular}{|c|c|c|c|c|c|c|c|c|}
\hline Study & Country & Target group & Setting & Design & Intervention (n) & Control (n) & Outcome & Follow-up \\
\hline Bryan et al ${ }^{12}$ & USA & $\begin{array}{l}\text { Active-duty United States Army } \\
\text { soldiers, adults, attending } \\
\text { emergency department } \\
\text { with suicidal ideation and/or } \\
\text { attempt }\end{array}$ & $\begin{array}{l}\text { Veterans Health } \\
\text { Administration } \\
\text { emergency } \\
\text { department }\end{array}$ & RCT & $\begin{array}{l}\text { CRP ( } n=32 \text { ) and E-CRP ( } n=33 \text { ); single session; CRP } \\
\text { (warning signs, coping strategies, social support, } \\
\text { Crisis resources) and referral to treatment; } \\
\text { E-CRP (CRP plus reasons for living) and referral } \\
\text { to treatment }\end{array}$ & $\begin{array}{l}\text { TAU }(n=32) ; \\
\quad \text { contract for safety }\end{array}$ & $\begin{array}{l}\text { Suicidal behaviour: } \\
\text { SASII, medical } \\
\text { records; } \\
\text { suicidal ideation: } \\
\text { BSS }\end{array}$ & 6 months \\
\hline Chen et al ${ }^{29}$ & Taiwan & $\begin{array}{l}\text { Referred to suicide prevention } \\
\text { centre in Kaohsiung } \\
\text { following suicide attempt }\end{array}$ & $\begin{array}{l}\text { Case management } \\
\text { services }\end{array}$ & RCT & $\begin{array}{l}\text { Control plus coping card }\left(n=250^{\mathrm{a}}\right) \text {; crisis postcard } \\
\text { (individualised coping strategies, crisis } \\
\text { resources) sent after } 3 \text { months }\end{array}$ & $\begin{array}{l}\text { Control }\left(n=363^{\mathrm{b}}\right) \text {; } \\
\text { case management for } 3 \text { months } \\
\text { (psychological support, coping } \\
\text { strategies, adherence to } \\
\text { treatment, individualised case- } \\
\text { work) }\end{array}$ & $\begin{array}{l}\text { Suicidal behaviour: } \\
\text { clinical notes }\end{array}$ & 6 months \\
\hline $\begin{array}{l}\text { Gysin-Maillart } \\
\text { et al }\end{array}$ & Switzerland & $\begin{array}{l}\text { Adults, admitted to emergency } \\
\text { department for suicide } \\
\text { attempt }\end{array}$ & $\begin{array}{l}\text { Emergency } \\
\text { department }\end{array}$ & RCT & $\begin{array}{l}\text { TAU and ASSIP ( }(n=60) \text {; three sessions; narrative } \\
\text { interview, reconstruction of suicidal action, } \\
\text { leaflet (long-term goals, warning signs and } \\
\text { personal safety strategies, crisis resources), } \\
\text { regular letters to participants for } 24 \text { months }\end{array}$ & $\begin{array}{l}\text { TAU }(n=60) \text {; enhanced TAU (care as } \\
\text { considered necessary by the } \\
\text { clinicians in charge), single } \\
\text { clinical interview }\end{array}$ & $\begin{array}{l}\text { Suicidal behaviour: } \\
\text { medical records; } \\
\text { suicidal ideation: } \\
\text { BSS }\end{array}$ & 24 months \\
\hline Miller et al ${ }^{17}$ & USA & $\begin{array}{l}\text { Adults, attending emergency } \\
\text { department with recent } \\
\text { suicide attempt or ideation }\end{array}$ & $\begin{array}{l}\text { Emergency } \\
\text { department }\end{array}$ & ITS & $\begin{array}{l}\text { ED-SAFE and screening ( }(=502) \text {; } \\
\text { secondary suicide risk screening, self- } \\
\text { administered safety plan (safe environment, } \\
\text { warning signs, coping strategies, important } \\
\text { things, social support, professional help), follow- } \\
\text { up calls }\end{array}$ & $\begin{array}{l}\text { Screening only }(n=377)^{C} \text { and TAU ( } n \\
\quad=497) ; \\
\text { secondary suicide risk screening } \\
\text { and care as usual; usual care at } \\
\text { each site }\end{array}$ & $\begin{array}{l}\text { Suicidal behaviour: } \\
\text { CSSRS, medical } \\
\text { records }\end{array}$ & 12 months \\
\hline Stanley et a $\left.\right|^{18}$ & USA & $\begin{array}{l}\text { USA military veterans, adults, } \\
\text { attending emergency } \\
\text { department for suicide } \\
\text { concerns }\end{array}$ & $\begin{array}{l}\text { Veterans Health } \\
\text { Administration } \\
\text { emergency } \\
\text { department }\end{array}$ & $\begin{array}{l}\text { Controlled } \\
\text { trial }\end{array}$ & $\begin{array}{l}\text { CAU and SPI ( }(n=1186) \text {; single session; SPI (warning } \\
\text { signs, coping strategies, social support, crisis } \\
\text { resources, safe environment), follow-up calls }\end{array}$ & $\begin{array}{l}\text { CAU }(n=454) \text {; assessment, } \\
\text { secondary evaluation, care as } \\
\text { needed, out-patient } \\
\text { appointment at discharge }\end{array}$ & $\begin{array}{l}\text { Suicidal behaviour, } \\
\text { medical records }\end{array}$ & 6 months \\
\hline Wang et $\mathrm{al}^{13}$ & Taiwan & $\begin{array}{l}\text { Adults, reporting to case } \\
\text { management services } \\
\text { following suicide attempt }\end{array}$ & $\begin{array}{l}\text { Case management } \\
\text { services }\end{array}$ & RCT & $\begin{array}{l}\text { TAU and crisis coping cards }(n=34) \text {; } \\
\text { 6-week coping card training sessions, coping } \\
\text { card (self-awareness of ideation, coping } \\
\text { strategies, crisis resources, local medical } \\
\text { information) }\end{array}$ & $\begin{array}{l}\text { TAU }(n=33) \text {; } \\
\text { case management (suicide crisis } \\
\text { assessment, emotional support, } \\
\text { referral) }\end{array}$ & $\begin{array}{l}\text { Suicidal behaviour: } \\
\text { clinical notes; } \\
\text { suicidal ideation: } \\
\text { BSRS }\end{array}$ & 3 months \\
\hline
\end{tabular}


(50.2\%) had attempted suicide at least once before enrolment. Not all studies reported on participants' mental health, ${ }^{13,29}$ but depression, ${ }^{17,18}$ affective disorders ${ }^{30}$ and adjustment disorders ${ }^{12}$ were mentioned as predominant comorbid disorders in other studies.

Suicidal behaviour was measured via interviews, ${ }^{12,17}$ medical records ${ }^{12,17,18,30}$ and clinical notes (i.e. recorded by a gatekeeper or clinician). ${ }^{13,29}$ In some studies, participants had all previously attempted suicide $(n=3)^{13,29,30}$ or were experiencing suicidal ideation and/or a recent suicide attempt $(n=2),{ }^{12,17}$ whereas the participants in one study were reported to have visited a hospital for suicide-related concerns. ${ }^{18}$ In two studies, professional groups (soldiers and military veterans) were involved, ${ }^{12,18}$ and the other studies comprised participants from the general population. ${ }^{13,17,29,30}$ Settings varied between general hospitals $(n=2),{ }^{17,30}$ military hospitals $(n=2)^{12,18}$ and case management services $(n=2){ }^{13,29}$ Participants of one study were in-patients, ${ }^{30}$ whereas all others were out-patients. ${ }^{12,13,17,18,29}$

All interventions were provided face to face by a clinician, and consisted of comparable safety plans. See Table 1 for an overview of safety planning components included in the interventions. In addition to coping strategies and sources of support, four studies included personal warning signs of an impending suicidal crisis. ${ }^{12,17,18,30}$ The safety plan was generally provided in person and on paper, ${ }^{12,13,17,18,30}$ although in one study it was sent to participants by post. ${ }^{29}$

\section{Primary outcome: suicidal behaviour}

Of the 3536 included participants, 348 engaged in suicidal behaviour during the follow-up period ( $n=150$ in the intervention condition; $n=198$ in the control condition). The incidence of suicidal behaviour ranged from 0 to $18.3 \%$ in intervention conditions, and 5.3 to $26.7 \%$ in control conditions (see Supplementary Appendix 3).

The relative risk of suicidal behaviour for participants who received an SPTI was 0.57 compared with TAU (95\% CI $0.41-$ $0.80, P=0.001 ; I^{2}=32.51 \%, 95 \%$ CI $0-71 \%$; NNT $=16$ ), indicating that the risk of suicidal behaviour was significantly reduced by $43 \%$ in the intervention condition (Fig. 2). A visual inspection of the forest plot indicated no outliers, as the effect sizes overlapped with the $95 \%$ confidence interval of the pooled effect size (see Fig. 2).

\section{Secondary outcome: suicidal ideation}

The mean effect size of the three studies examining the effects of SPTIs on suicide ideation (combined $N=283$ ) was non-significant
( $g=0.69,95 \%$ CI -0.04 to $1.42, P=0.06 ; I^{2}=87.60 \%$ ) (see Fig. 3 and Supplementary Appendix 3). ${ }^{10,20,26}$

\section{Methodological quality}

In terms of methodological quality, participants in two studies were not randomised, and in two other studies, the randomisation was based on a national identification number. Hence, results of these four studies were considered to be at high risk of bias (Table 2). In five studies, deviations from the intended interventions (such as problems in recruitment or in delivering the intervention) were reported. All studies apparently handled incomplete outcome data correctly. In two studies, no description was given of the assessments and assessors, hence bias in outcome measurement was evaluated to be high. Five studies were considered at moderate risk of bias in their selection of the reported outcome measures. Overall, one study was considered to be at low risk of bias, one at moderate risk of bias and four at high risk of bias.

\section{Publication bias}

The inspection of the funnel plot suggested publication bias (Fig. 4), and that was supported by a significant Egger's test of the intercept $(P=0.001)$. Duval and Tweedie's trim-and-fill procedure suggested that three studies in favour of TAU, with a smaller s.e., might be missing from the research literature. With those studies imputed, the relative risk for engagement in suicidal behaviour came to 0.71 (95\% CI 0.59-0.86), implying that the relative risk for patients who received an SPTI would be closer to 1, as compared with TAU, but would remain significant.

\section{Subgroup and sensitivity analyses}

We assessed possible sources of the heterogeneity, using methodological quality, setting and population as potential moderators in subgroup analyses, but found no significant differences between groups (Table 3 ).

We tested the robustness of the effect on suicidal behaviour in additional sensitivity analyses, yet the pooled relative risk remained significant after exclusion of the studies with the highest or lowest relative risk (relative risk $0.481, P=0.000$ versus relative risk $0.598, P=0.001$ ). A significant pooled relative risk was also found when we distinguished between studies with large samples $(N>500)$ and smaller samples (large samples: relative risk 0.688 ,

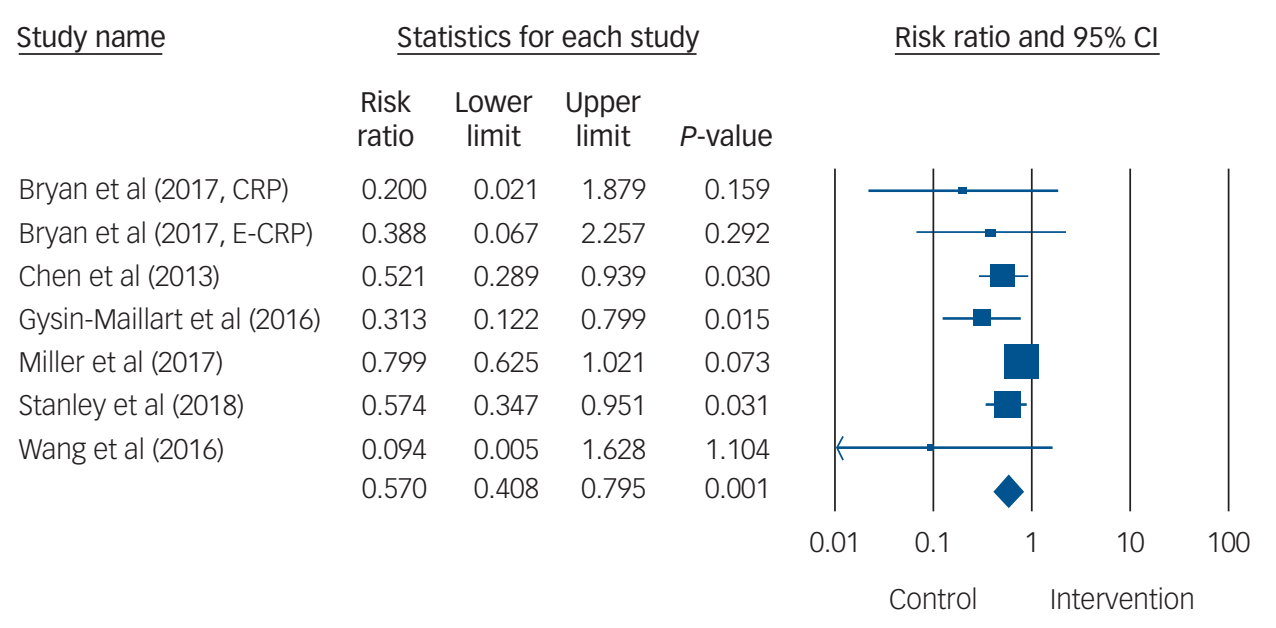


$\underline{\text { Study name }}$

Bryan et al (2017, CRP)
Bryan et al (2017, E-CRP)
Gysin-Maillart et al (2017)
Wang et al (2016)

Statistics for each study

Hedges'g Lower Upper limit limit

$\begin{array}{rrr}0.541 & -0.060 & -0.141 \\ 0.724 & 0.120 & 1.329 \\ -0.028 & -0.383 & 0.328 \\ 1.592 & 1.043 & 2.141 \\ 0.692 & -0.039 & 1.423\end{array}$

Hedges' $\mathrm{g}$ and $95 \% \mathrm{Cl}$

$P$-value

0.078
0.019
0.878
0.000
0.064

$\mid$

$-2.00$
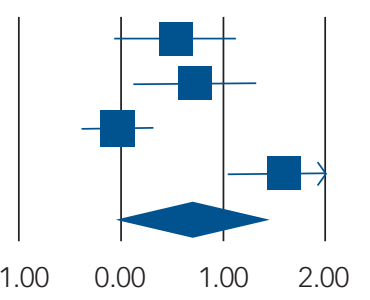

Control Intervention

Fig. 3 Forest plot for suicidal ideation. CRP, standard crisis response plan; E-CRP, enhanced crisis response plan.

\begin{tabular}{|c|c|c|c|c|c|c|}
\hline Study & Randomisation & $\begin{array}{l}\text { Deviation from intended } \\
\text { interventions }\end{array}$ & $\begin{array}{l}\text { Missing outcome } \\
\text { data }\end{array}$ & $\begin{array}{l}\text { Measurement of } \\
\text { outcomes }\end{array}$ & $\begin{array}{l}\text { Selection of reported } \\
\text { results }\end{array}$ & Overall bias \\
\hline Bryan et al ${ }^{12}$ & LoW & Moderate & Low & Low & Moderate & Moderate \\
\hline Chen et $\mathrm{al}^{29}$ & High & High & Low & High & Moderate & High \\
\hline $\begin{array}{l}\text { Gysin-Maillart } \\
\text { et } \mathrm{al}^{30}\end{array}$ & Low & Low & Low & Low & LoW & Low \\
\hline Miller et al ${ }^{17}$ & High & Moderate & Low & LoW & Moderate & High \\
\hline Stanley et $\mathrm{al}^{18}$ & High & Moderate & Low & Low & Moderate & High \\
\hline Wang et $\mathrm{al}^{13}$ & High & High & Low & High & Moderate & High \\
\hline
\end{tabular}

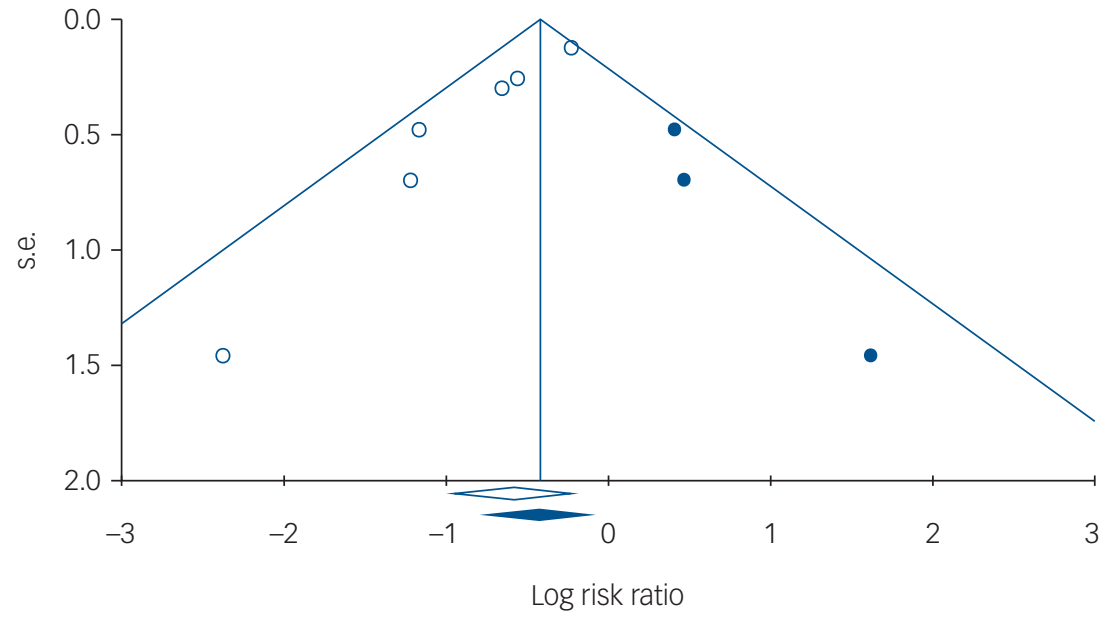

Fig. 4 Funnel plot of s.e., by log risk ratio.

$P=0.006$; small samples: relative risk $0.285, P=0.001)$, and between studies with and without randomisation (randomised: relative risk $0.414, P=0.000$; not randomised: relative risk $0.713, P=0.032$ ).

\section{Discussion}

This meta-analysis found that SPTIs for suicide prevention were associated with reductions in suicidal behaviour, but no effect was identified on suicidal ideation. Overall, six studies were included for analysis. SPTIs were associated with a risk of engagement in suicidal behaviour that was 0.57 times the risk of patients without such an intervention. This means that the risk of suicidal behaviour was reduced by $43 \%(\mathrm{NNT}=16)$ for patients who were utilising an SPTI. The findings from sensitivity analyses supported a robust effect. The observed effect is in line with the hypothesis that safety plans reduce the imminent risk of engagement in suicidal behaviour by presenting alternative coping strategies and sources of support. ${ }^{10,11}$ The outcome also appears consistent with clinicians' beliefs in the effectiveness of safety planning. ${ }^{14,15}$ However, other interventions may be needed to reduce suicidal ideation.

The lack of an effect from SPTIs on suicidal ideation might be explained by the fact that suicidal ideation was not directly targeted 


\begin{tabular}{|c|c|c|c|c|c|c|}
\hline & Number of comparisons & Relative risk & $95 \% \mathrm{Cl}$ & $1^{2}$ & $95 \% \mathrm{Cl}$ & $P$-value ${ }^{a}$ \\
\hline All studies $(N=6)$ & 7 & 0.570 & $0.408-0.795, P=0.001$ & 32.505 & 0-71\% & \\
\hline \multicolumn{7}{|l|}{ Subgroup analyses $(n=7)$} \\
\hline \multicolumn{7}{|l|}{ Quality of study } \\
\hline Low risk of bias & 3 & 0.309 & $0.142-0.672, P=0.003$ & 0.00 & 0-90\% & \multirow[t]{2}{*}{0.082} \\
\hline High risk of bias & 4 & 0.651 & $0.471-0.900, P=0.009$ & 34.230 & 0-77\% & \\
\hline \multicolumn{7}{|l|}{ Setting } \\
\hline Emergency department & 5 & 0.595 & $0.404-0.875, P=0.008$ & 35.277 & $0-76 \%$ & \multirow[t]{2}{*}{0.542} \\
\hline Case management & 2 & 0.339 & $0.118-1.351$ & 24.926 & Not applicable & \\
\hline \multicolumn{7}{|l|}{ Population } \\
\hline General population & 4 & 0.543 & $0.320-0.921, P=0.024$ & 56.008 & 0-85\% & \multirow[t]{2}{*}{0.955} \\
\hline Other & 3 & 0.532 & $0.331-0.855, P=0.009$ & 0.00 & 0-90\% & \\
\hline
\end{tabular}

by this type of intervention. Such a supposition is supported by a recent systematic review by McCabe et al on brief psychological interventions for suicide prevention, which suggested that such interventions may alter behaviours of individuals at risk of suicide, but their level of cognitive distress remains unaffected. ${ }^{7}$ Another explanation for the lack of effect on suicidal ideation may lie in the fact that suicidal thoughts are known to fluctuate over time; ${ }^{31}$ hence, possible initial effects might have abated by the end of follow-up. Psychotherapeutic interventions that are known to be effective in reducing suicidal ideation include cognitive-behavioural therapy and dialectical behaviour therapy. ${ }^{5,6}$

\section{Strengths and limitations}

To the best of our knowledge, this paper is the first to report a metaanalysis on SPTIs for suicide prevention. Our meta-analysis was adequately powered and supported by sensitivity analyses. Nonetheless, our results should be interpreted with caution because of several limitations. First, the field of SPTIs is relatively new, thus only a few controlled studies could be included in the analyses. Second, not all of the included studies were randomised, implying limited comparability. Third, our findings cannot be generalised to adolescents and children, as only adults were included in the analyses. Fourth, we did not include the term 'self-harm' in our search string because the known SPTIs were developed specifically as suicide prevention tools. However, in response to a reviewer, we have run a post hoc search including self-harm as a search term, and this did not yield any additional studies meeting our inclusion criteria. Another limitation is the low methodological quality of the studies, which may have affected outcomes. On the other hand, our use of a single bias risk assessment tool for all studies could have distorted results from non-randomised controlled studies. Furthermore, the studies varied amongst themselves, including differences in the measurement of 'suicide attempt' and in the length of follow-up. That said, variations in terms of quality, settings and included populations did not explain the heterogeneity in this meta-analysis. Other differences between studies might offer explanations; for example, in terms of inclusion criteria or the content of TAU (such as possible variations in the care needed in different countries). Moreover, since the studies implemented safety planning in different ways, future research is required to determine the active ingredients of SPTIs, and to assess whether follow-up telephone calls play a role.

\section{Implications for the future}

From a clinical point of view, the present study has important implications. SPTIs are already widely implemented, and they are identified as best practice for suicide prevention by the National Institute for Health and Care Excellence and the Suicide Prevention Resource Center. So far, implementation has been largely based on clinicians' beliefs about the value of the interventions, ${ }^{14,15}$ but our study has now demonstrated their effectiveness in reducing suicidal behaviour. This suggests that safety planning should continue to be identified as best practice for the prevention of suicidal behaviour in individuals at risk of suicide, and should be strongly recommended in clinical practice and guidelines for suicide prevention.

Higher-quality, randomised controlled studies on the effectiveness of SPTIs will be needed to replicate the results of the current meta-analysis. For now, SPTIs appear to be an effective strategy to reduce suicidal behaviour.

Chani Nuij (D), MSc, Section Clinical Psychology, Amsterdam Public Health Research Institute, Vrije Universiteit Amsterdam, The Netherlands; Wouter van Ballegooijen (1D), PhD, Section Clinical Psychology, Amsterdam Public Health Research Institute, Vrije Universiteit Amsterdam, The Netherlands; Department of Research and Innovation, GGZ inGeest Specialized Mental Health Care, The Netherlands; Department of Psychiatry, Amsterdam Public Health Research Institute, Amsterdam University Medical Center, The Netherlands; Derek de Beurs, PhD, Section Clinical Psychology, Amsterdam Public Health Research Institute, Vrije Universiteit Amsterdam, The Netherlands; and Department of epidemiology, Trimbos-institute, The Netherlands; Dilfa Juniar, MPsi, Section Clinical Psychology, Amsterdam Public Health Research Institute, Vrije Universiteit Amsterdam, The Netherlands; and Faculty of Psychology, Universitas YARSI, Indonesia; Annette Erlangsen (ID, PhD, Danish Research Institute for Suicide Prevention, Mental Health Centre Copenhagen, Denmark; Department of Mental Health, Johns Hopkins Bloomberg School of Public Health, USA; and Centre for Mental Health Research, Australian National University, Australia; Gwendolyn Portzky, PhD, Flemish Centre of Expertise in Suicide Prevention, Department of Head and Skin, Faculty of Medicine and Health Science, Ghent University, Belgium; Rory C. O'Connor, PhD,

Suicidal Behaviour Research Laboratory, Institute of Health and Wellbeing, University of Glasgow, UK; Johannes H. Smit, PhD, Department of Research and Innovation, GGZ inGeest Specialized Mental Health Care, The Netherlands; and Department of Psychiatry, Amsterdam Public Health Research Institute, Amsterdam University Medical Center, The Netherlands; Ad Kerkhof, PhD, Section Clinical Psychology, Amsterdam Public Health Research Institute, Vrije Universiteit Amsterdam, The Netherlands; Heleen Riper (D), PhD, Section Clinical Psychology, Amsterdam Public Health Research Institute, Vrije'

Universiteit Amsterdam, The Netherlands; Department of Research and Innovation, GGZ inGeest Specialized Mental Health Care, The Netherlands; and Department of Psychiatry, Amsterdam Public Health Research Institute, Amsterdam University Medical Center, The Netherlands

Correspondence: Chani Nuij. Email: c.nuij@vu.nl

First received 12 Oct 2020, final revision 30 Mar 2021, accepted 30 Mar 2021

\section{Supplementary material}

To view supplementary material for this article, please visit https://doi.org/10.1192/bjp.2021.50.

\section{Data availability}

Data availability is not applicable to this article as no new data were created or analysed in this study.

\section{Acknowledgements}

We thank Caroline Planting for performing the literature search, and Michael Dallas for editing the manuscript in preparation for submission. 


\section{Author contributions}

C.N. had full access to all data in the study and takes responsibility for integrity of the data and accuracy of data analyses. C.N., W.V.B. and H.R. were responsible for the study concept and design. C.N., W.V.B. and D.J. contributed to the collecting and processing of the data. C.N. analysed the data and discussed the results and interpretation, with W.V.B. and H.R.. C.N. drafted the manuscript. C.N., W.v.B., D.d.B., D.J., A.E., G.P., R.C.O., J.H.S., A.K. and H.R. critically revised the manuscript.

\section{Funding}

This study is funded by ZonMw (Netherlands Organisation for Health Research and Development), project number 537001008

\section{Declaration of interest}

None.

\section{References}

1 World Health Organization (WHO). National Suicide Prevention Strategies: Progress, Examples and Indicators. WHO, 2018 (https://www.who.int/mental_health/suicide-prevention/national_strategies_2019/en/).

2 World Health Organization (WHO). Preventing Suicide: A Global Imperative. WHO, 2014 (https://www.who.int/mental_health/suicide-prevention/world report_2014/en/).

3 May AM, Klonsky ED. What distinguishes suicide attempters from suicide ideators? A meta-analysis of potential factors. Clin Psychol Sci Pract 2016; 23 (1): $5-20$.

4 Nock MK, Borges G, Bromet EJ, Alonso J, Angermeyer M, Beautrais A, et al. Cross-national prevalence and risk factors for suicidal ideation, plans and attempts. Br J Psychiatry 2008; 192(2): 98-105.

5 Mann JJ, Apter A, Bertolote J, Beautrais A, Currier D, Haas A, et al. Suicide prevention strategies. JAMA 2005; 294(16): 2064

6 Zalsman G, Hawton K, Wasserman D, van Heeringen K, Arensman E, Sarchiapone M, et al. Suicide prevention strategies revisited: 10-year systematic review. Lancet Psychiatry 2016; 3(7): 646-59.

7 McCabe R, Garside R, Backhouse A, Xanthopoulou P. Effectiveness of brief psychological interventions for suicidal presentations: a systematic review. BMC Psychiatry 2018; 18: 120.

8 Doupnik SK, Rudd B, Schmutte T, Worsley D, Bowden CF, McCarthy E, et al. Association of suicide prevention interventions with subsequent suicide attempts, linkage to follow-up care, and depression symptoms for acute care settings. JAMA Psychiatry 2020; 77(10): 1021-30.

9 Brown GK, Ten Have T, Henriques GR, Xie SX, Hollander JE, Beck AT. Cognitive therapy for the prevention of suicide attempts. JAMA 2005; 294(5): 563.

10 Stanley B, Brown G, Brent D, Wells K, Poling K, Curry J, et al. Cognitivebehavioral therapy for suicide prevention (CBT-SP): treatment model, feasibility, and acceptability. J Am Acad Child Adolesc Psychiatry 2009; 48(10): 1005-13.

11 Stanley B, Brown GK. Safety planning intervention: a brief intervention to mitigate suicide risk. Cogn Behav Pract 2012; 19(2): 256-64.

12 Bryan CJ, Mintz J, Clemans TA, Leeson B, Burch TS, Williams SR, et al. Effect of crisis response planning vs. contracts for safety on suicide risk in U.S. army soldiers: a randomized clinical trial. J Affect Disord 2017; 212: 64-72.
13 Wang YC, Hsieh LY, Wang MY, Chou CH, Huang MW, Ko HC. Coping card usage can further reduce suicide reattempt in suicide attempter case management within 3-month intervention. Suicide Life Threat Behav 2016; 46(1): 106-20.

14 Chesin MS, Stanley B, Haigh EAP, Chaudhury SR, Pontoski K, Knox KL, et al. Staff views of an emergency department intervention using safety planning and structured follow-up with suicidal veterans. Arch Suicide Res 2017; 21(1): 127-37.

15 Setkowski K, van Balkom AJLM, Dongelmans DA, Gilissen R. Prioritizing suicide prevention guideline recommendations in specialist mental healthcare: a Delphi study. BMC Psychiatry 2020; 20: 55.

16 Kayman DJ, Goldstein MF, Wilsnack J, Goodman M. Safety planning for suicide prevention. Curr Treat Options Psychiatry 2016; 3(4): 411-20.

17 Miller IW, Camargo CAJ, Arias SA, Sullivan AF, Allen MH, Goldstein AB, et al. Suicide prevention in an emergency department population: the ED-SAFE study. JAMA Psychiatry 2017; 74(6): 563-70.

18 Stanley B, Brown GK, Brenner LA, Galfalvy HC, Currier GW, Knox KL, et al. Comparison of the safety planning intervention with follow-up vs usual care of suicidal patients treated in the emergency department. JAMA Psychiatry 2018; 75(9): 894-900.

19 Moher D. Preferred reporting items for systematic reviews and meta-analyses: the PRISMA statement. Ann Intern Med 2009; 151(4): 264

20 Cohen J. Statistical Power Analysis for the Behavioral Sciences, Revised Edition. Academic Press, 2013

21 Mendes D, Alves C, Batel-Marques F. Number needed to treat (NNT) in clinical literature: an appraisal. BMC Med 2017; 15: 112

22 Borenstein M, Hedges L, Higgins J, Rothstein H. Introduction to Meta-Analysis (1st edn). John Wiley and Sons, 2009

23 Egger M, Smith GD, Schneider M, Minder C. Bias in meta-analysis detected by a simple, graphical test. BMJ 1997; 315(7109): 629-34.

24 Duval S, Tweedie R. Trim and fill: a simple funnel-plot-based method of testing and adjusting for publication bias in meta-analysis. Biometrics 2000; 56(2): 455-63.

25 Higgins JPT. Measuring inconsistency in meta-analyses. BMJ 2003; 327(7414): 557-60

26 Ioannidis JPA, Patsopoulos NA, Evangelou E. Uncertainty in heterogeneity estimates in meta-analyses. BMJ 2007; 335(7626): 914-6.

27 Orsini N, Bottai M, Higgins J, Buchan I. HETEROGI: Stata Module to Quantify Heterogeneity in a Meta-Analysis. Statistical Software Components, 2006 (http://fmwww.bc.edu/repec/bocode/h/heterogi.ado).

28 Sterne JAC, Savović J, Page MJ, Elbers RG, Blencowe NS, Boutron I, et al. RoB 2: a revised tool for assessing risk of bias in randomised trials. BMJ 2019; 366 : 14898

29 Chen W-J, Ho C-K, Shyu S-S, Chen C-C, Lin G-G, Chou L-S, et al. Employing crisis postcards with case management in Kaohsiung, Taiwan: 6-month outcomes of a randomised controlled trial for suicide attempters. BMC Psychiatry 2013; 13: 191.

30 Gysin-Maillart A, Schwab S, Soravia L, Megert M, Michel K. A novel brief therapy for patients who attempt suicide: a 24-months follow-up randomized controlled study of the Attempted Suicide Short Intervention Program (ASSIP). PLOS Med 2016; 13(3): e1001968.

31 Czyz EK, King CA, Biermann BJ. Motivational interviewing-enhanced safety planning for adolescents at high suicide risk: a pilot randomized controlled trial. J Clin Child Adolesc Psychol 2019; 48(2): 250-62. 